\title{
Identification and diversity of bovine major histocompatibility complex class II haplotypes in Japanese Black and Holstein cattle in Japan
}

\author{
T. Miyasaka, ${ }^{*}+$ S.-N. Takeshima, ${ }^{*}$ H. Sentsui, $\dagger$ and Y. Aida* \\ *Viral Infectious Diseases Unit, RIKEN, 2-1 Hirosawa, Wako, Saitama 351-0198, Japan \\ †School of Veterinary Medicine, Nihon University, 1866 Kameino, Fujisawa, Kanagawa 252-8510, Japan
}

\begin{abstract}
Bovine leukocyte antigen $(B o L A)$, the major histocompatibility complex of cattle, is one of the most polymorphic gene clusters. We genotyped a population of 109 Japanese Black and 39 Holstein cattle to analyze their BoLA class II haplotypes, BoLA-DRB3 locus, 5 BoLA-DQA loci, and $5 B o L A-D Q B$ loci. We identified 26 previously reported DRB3 alleles, 22 previously reported and 3 new $D Q A$ alleles, and 24 previously reported and 6 new $D Q B$ alleles. A dendrogram was constructed based on the predicted amino acid sequences of the $\alpha 1$ or $\beta 1$ domains encoded by $B o L A-D Q A$ or $-D Q B$ alleles, which revealed that $D Q A$ alleles were clustered into 5 loci, whereas $D Q B$ alleles could not be clearly assigned to specific $D Q B$ loci. The $B o L A-D R B 3-D Q A-D Q B$ haplotypes were sorted by sequential analytical processes, and 42 distinct haplotypes, including 11 previously published haplotypes and 31 novel haplotypes, were defined. Strong linkage disequilibrium was present in the $B o L A$ genes. We also compared DRB3-DQA1 haplotype frequencies between 507 Japanese Black and 143 Holstein cattle. Thirtynine $D R B 3-D Q A 1$ haplotypes were identified, including 29 haplotypes from Japanese Black and 22 haplotypes from Holstein cattle. The majority of the haplotypes could be identified in both breeds, although several haplotypes were identified in only a single breed. This is the first report presenting a detailed study of the BoLA class II haplotype in Japanese Black and Holstein cattle in Japan.
\end{abstract}

Key words: bovine leukocyte antigen class II haplotype, BoLA-DRB3, BoLA-DQA, BoLA-DQB

\section{INTRODUCTION}

The major histocompatibility complex (MHC) has a crucial role in determining immune responsiveness. The MHC system in cattle is known as the bovine leukocyte antigen $(\boldsymbol{B o L} \boldsymbol{A})$ and is encoded at the chromosome

Received June 14, 2011.

Accepted September 16, 2011.

${ }^{1}$ Corresponding author: aida@riken.jp
23 within a 4,000-kb stretch of DNA, which contains more than 154 tightly linked genes (Elsik et al., 2009). The BoLA class II genes are divided into separate regions, IIa and IIb, separated by about one-third of the chromosome's length, which is the most notable feature of cattle and other ruminant $M H C$ genes (Elsik et al., 2009). The IIa region includes the functional $M H C$ class II genes $D R$ and $D Q$. Cattle have $1 D R A$ locus, $3 D R B$ loci, $5 D Q A$ loci, and $5 D Q B$ loci, which have arisen because of gene duplication, and express $1 D R$ gene pair (DRA and $D R B)$ and 1 or $2 D Q$ gene pairs per haplotype (Lewin et al., 1999; Takeshima and Aida, 2006). Among these genes, DRB3, $D Q A$, and $D Q B$ genes exhibit high polymorphism, whereas BoLA-DRA is monomorphic. To date, 119 DRB3, 51 $D Q A$, and $72 D Q B$ alleles have been identified in the Immuno Polymorphism Database (IPD)-MHC database (http://www.ebi.ac.uk/ipd/mhc/bola). Thus, DQ is less polymorphic than DR. The DRB3 gene is the only functional $D R B$ gene, which suggests that DR molecules alone are insufficient to present a sufficiently broad spectrum of antigens and that DQ molecules are equally important. In support of this hypothesis, DQ molecules have been shown to function as effectively as DR molecules (Aida, 1995; Glass et al., 2000). For these reasons, duplicated $D Q A$ and $D Q B$ genes are thought to make a significant contribution to the diversity of antigen-presenting molecules in cattle.

Polymorphisms in BoLA class II genes have been reported to be responsible for the outcomes of infectious diseases such as neosporosis, Lone Star tick, clinical mastitis, and enzootic bovine leukosis (Xu et al., 1993; Takeshima and Aida, 2006; Untalan et al., 2007; Takeshima et al., 2008b; Schwab et al., 2009). However, it is unclear whether specific $B o L A$ class II loci are definitely related to the disease, or whether other linked genes are responsible for the association. Interpreting these studies has been difficult because the full-genome sequence and genomic organization of the $B o L A$ region has only recently been fully established. Polymorphisms in cattle $M H C$ genes have been relatively well studied but the majority of studies have focused on single loci, commonly the BoLA-DRB3 gene, and have given little 
attention to the multiple $D Q A$ and $D Q B$ genes (Mikko and Andersson, 1995; Ballingall et al., 1997, 1998; Takeshima et al., 2002, 2003, 2009, 2008a; Wang et al., 2005, 2007). Furthermore, most of the reported BoLA class II $D R-D Q$-linked haplotypes have focused on Holstein cattle and have used a relatively small sample population (Lewin et al., 1999; Glass et al., 2000; Russell, 2000; Park et al., 2004; Norimine and Brown, 2005; Staska et al., 2005). Indeed, no published data exist on $B o L A$ class II $D R-D Q$-linked haplotypes in Japanese Black cattle, a breed used to upgrade Japanese native cattle, which have a significant genetic contribution from several European cattle breeds. In addition, some haplotype analyses have been conducted only by PCR restriction fragment length polymorphism, so limited information is available about $B o L A$ class II haplotypes. Thus, a full picture of BoLA class II haplotypes remains to be elucidated.

Previously, we sequenced alleles of $B o L A-D R B 3$ and -DQA1, from 650 Japanese cattle using PCR sequencebased typing (SBT), and characterized the allelic distribution of BoLA-DRB3 and -DQA1 genes on different farms of Japanese Black and Holstein cattle in Japan (Miyasaka et al., 2011). In this study, we characterized the distribution of $B o L A-D R B 3-D Q A-D Q B$ haplotypes of the same samples (Miyasaka et al., 2011). First, a total of 148 cattle (109 Japanese Black and 39 Holstein cattle) were genotyped at the $B o L A-D R B 3$ locus, $5 B o L A-D Q A$ loci, and $5 B o L A-D Q A$ loci, and their BoLA-DRB3-DQA-DQB haplotypes were identified. Following that, the frequencies of the identified $B o L A$ DRB3-DQA1 haplotypes were compared with those of an additional 507 Japanese Black cattle and 143 Holstein cattle. The results will contribute to studies investigating disease susceptibility genes in the $B o L A$ region and may lead to improvements in livestock health.

\section{MATERIALS AND METHODS}

\section{Sample Population and Genomic DNA Extraction}

Blood samples from 507 Japanese Black and 143 Japanese Holstein cattle were collected from 6 herds in the Gifu and Fukuoka regions of Japan. The samples were the same as those used previously to analyze the frequencies of the BoLA-DRB3 and DQA1 alleles (Miyasaka et al., 2011). Genomic DNA was isolated from whole blood using Wizard Genomic DNA Purification kits (Promega KK, Tokyo, Japan).

\section{BoLA-DRB3 and BoLA-DQA1 Alleles}

The 26 distinct BoLA-DRB3 alleles and 15 distinct $B o L A-D Q A 1$ alleles were previously defined by PCR-
SBT methods (Miyasaka et al., 2011) and used in this study.

\section{BoLA-DQA2/3/4 Typing}

The DQA2/3/4 typing was conducted by semi-nested PCR using the Ex Taq PCR reaction kit (Takara Bio Inc., Shiga, Japan). Polymerase chain reaction of the $D Q A 2 / 3$ exon 2 region was performed using primer pair DQA2intron2F (TTTGCTTAGAGACATTGTGC) and QA006 (CACTTACCATTGATAACAGG). The thermal cycling profile was as follows: initial denaturation for $2 \mathrm{~min}$ at $94^{\circ} \mathrm{C} ; 25$ cycles of $20 \mathrm{~s}$ at $94^{\circ} \mathrm{C}, 20$ s at $50^{\circ} \mathrm{C}$, and $20 \mathrm{~s}$ at $72^{\circ} \mathrm{C}$; and final extension for 5 min at $72^{\circ} \mathrm{C}$. The resulting amplicon was used as the template for a second PCR reaction using primer pair DQA2intL06ver2 (TTTTCCACCTTYYTGCTCCT) and QA006. The thermal cycling profile was as follows: initial denaturation for 2 min at $94^{\circ} \mathrm{C} ; 30$ cycles of 20 $\mathrm{s}$ at $94^{\circ} \mathrm{C}, 20 \mathrm{~s}$ at $56^{\circ} \mathrm{C}$, and $20 \mathrm{~s}$ at $72^{\circ} \mathrm{C}$; and final extension for $5 \mathrm{~min}$ at $72^{\circ} \mathrm{C}$. The PCR product was purified with an ExoSAP-IT PCR product purification kit (USB Corp., Cleveland, OH) and sequenced with primer pair DQA2intL06ver2 and QA006 using the ABI PRISM BigDye Terminator Cycle Sequencing Ready Reaction Kits (Applied Biosystems, Foster City, CA).

In cases where we identified more than 3 alleles from each individual, PCR products were cloned into pBluescript II SK(+) (Cosmo Bio Co., Tokyo, Japan). The PCR products of at least 6 positive clones were sequenced using the ABI PRISM BigDye Terminator Cycle Sequencing Ready Reaction Kits. The sequence data were analyzed using Assign 400ATF version 1.0.2.41 software (Conexio Genomics, Fremantle, Australia).

\section{BoLA-DQA5 Typing}

The PCR for the BoLA-DQA5 exon 2 region was performed as previously described (Gelhaus et al., 1999). Amplicon purification, sequence processing, and data analysis were carried out as described for DRB3 typing.

\section{BoLA-DQB Typing}

The BoLA-DQB was typed using KOD plus PCR reaction kit (Toyobo, Tokyo, Japan) as described by Wang et al. (2007). Amplicon purification, sequence processing, and data analysis were carried out as described for DRB3 typing.

In cases where we identified more than 3 alleles from each individual, $\mathrm{PCR}$ products were cloned into pBluescript II SK $(+)$ and the PCR products of at least 6 positive clones were sequenced by the ABI PRISM 


\begin{tabular}{|c|c|c|c|c|c|c|c|c|c|c|c|}
\hline \multicolumn{2}{|c|}{ Haplotype designation } & \multirow[b]{2}{*}{$D R B 3^{2}$} & \multirow[b]{2}{*}{$D Q A 1^{2}$} & \multirow[b]{2}{*}{$D Q A 2^{2,3}$} & \multirow[b]{2}{*}{$D Q A 4^{2,3}$} & \multirow[b]{2}{*}{$D Q A 5^{2,3}$} & \multirow[b]{2}{*}{$D Q B^{2,3,4}$} & \multicolumn{2}{|c|}{ Japanese Black } & \multicolumn{2}{|c|}{ Holstein } \\
\hline Authors' & Official $^{1}$ & & & & & & & $\begin{array}{l}\text { Homozygosity } \\
\qquad(\mathrm{n}=8)^{5}\end{array}$ & $\begin{array}{l}\text { Heterozygosity } \\
\quad(\mathrm{n}=101)^{5}\end{array}$ & $\begin{array}{l}\text { Homozygosity } \\
\quad(\mathrm{n}=8)^{5}\end{array}$ & $\begin{array}{l}\text { Heterozygosity } \\
\quad(\mathrm{n}=31)^{5}\end{array}$ \\
\hline $0101 \mathrm{~A}$ & DH24A & *0101 & ${ }^{*} 0101$ & & & & $* 0101$ & & 1 & 3 & 8 \\
\hline $0201 \mathrm{~A}$ & DH07A & *0201 & ${ }^{*} 0203(1)$ & & & & *0201 & 2 & 26 & & 7 \\
\hline $0501 \mathrm{~A}$ & DH01A & $* 0501$ & & *22021 & & & *1301 & & & & 2 \\
\hline $0502 \mathrm{~A}$ & & *0502 & & *2901 & $*_{2703}$ & & *3101 & & 5 & & \\
\hline $0503 \mathrm{~A}$ & & *0503 & ${ }^{*} 0101$ & & & & *2702 & 1 & 26 & & \\
\hline $0504 \mathrm{~A}$ & & *0504 & & & & & & & 7 & & \\
\hline $0601 \mathrm{~A}$ & & *0601 & & & & & *0302 & & & & 1 \\
\hline $0701 \mathrm{~A}$ & DH28A & $* 0701$ & $* 0101$ & *22031 & & & *0103 & & 4 & & 1 \\
\hline 0801A & & ${ }^{*} 0801$ & ${ }^{*} 0801$ & *22031 & & $*_{2801}$ & ${ }^{*} 0801$ & & 1 & & \\
\hline $0801 \mathrm{~B}$ & DH21A & ${ }^{*} 0801$ & ${ }^{*} 0801$ & & & *2801 & *0801, *2001 & & & & \\
\hline $0801 \mathrm{C}$ & & $* 0801$ & *1203 & *2201 & & & & & 1 & & \\
\hline $0801 \mathrm{D}$ & & $* 0801$ & & *22031 & & *2801 & & & 3 & & \\
\hline $0901 \mathrm{~A}$ & DH11C & *0901 & *1203 & *2201 & & & ${ }^{*} 1006, * 0901$ & & 3 & & \\
\hline 0902A & DH11A & *0902 & *0204 & & & & *0301 & & & & \\
\hline $0902 B$ & & *0902 & *0204 & & & & *1803 & & & & 7 \\
\hline $0902 \mathrm{C}$ & & *0902 & ${ }^{*} 0204$ & & & & $*_{1807}$ & & 10 & & \\
\hline $1001 \mathrm{~A}$ & & *1001 & *10012 & *2101 & & & $* \overline{10021}, * 0901$ & & & 1 & 1 \\
\hline 1001B & & *1001 & *10012 & *2206 & & & *10021, *1402 & & 11 & & \\
\hline $1001 \mathrm{C}$ & DH03A & *1001 & *10012 & & & & *1003, *0902 & & & & \\
\hline $1101 \mathrm{~A}$ & DH22H & *1101 & $*_{10011}$ & *2206 & & & $*_{10021,} *_{1402}$ & & 10 & & 4 \\
\hline $1101 \mathrm{~B}$ & DH22E & *1101 & *10012 & *2101 & & & *10021, *2902 & & & & 1 \\
\hline $1101 \mathrm{C}$ & & *1101 & *1301 & & & & $*_{1802}$ & & 3 & & \\
\hline $1103 \mathrm{~A}$ & & *1103 & *0203(2) & & & & *3602 & & 1 & & \\
\hline $1201 \mathrm{~A}$ & & *1201 & *10011 & *2206 & & & $*_{10021}, *_{1402}$ & & 8 & & \\
\hline $1201 \mathrm{~B}$ & DH08A & *1201 & *12011 & *2201 & & & $*_{1005,} *_{1201}$ & & 2 & 1 & 5 \\
\hline $1301 \mathrm{~A}$ & & *1301 & & & $*_{27011}$ & & & & 1 & & \\
\hline $1302 \mathrm{~A}$ & & *1302 & & & $*_{27011}$ & & & 1 & 3 & & 1 \\
\hline 14011A & & $*_{14011}$ & *10012 & *22021 & & & $*_{1} 10021, *_{1301}$ & & 3 & & \\
\hline 14011B & DH27A & $*_{14011}$ & $*_{1401}$ & & & & $*_{1401}$ & & & & 5 \\
\hline $1501 \mathrm{~A}$ & & $*_{1501}$ & *10011 & $*_{2101}$ & & & *10021, *2903 & & 1 & & \\
\hline 1501B & DH16A & *1501 & *10011 & *22021 & & & ${ }^{*} 0102,{ }^{* 1101}$ & & & & \\
\hline $1501 \mathrm{C}$ & DH16A & *1501 & *10011 & *22021 & & & $*_{10021,}^{* 1301}$ & & 13 & 3 & 5 \\
\hline 1501D & & *1501 & $*_{10012}$ & *2101 & & & *10021, *0901 & & & & 1 \\
\hline $1601 \mathrm{~A}$ & DH10C & *1601 & *10011 & *2002 & & & & & & & \\
\hline 1601B & & *1601 & *10012 & *22021 & & & *10021, *1302 & 3 & 39 & & \\
\hline $1601 \mathrm{C}$ & & *1601 & *12021 & *22021 & & & $*_{1001,}^{* 1301}$ & 1 & 13 & & \\
\hline $1701 \mathrm{~A}$ & & $*_{1701}$ & & & *3001 & & & & & & 2 \\
\hline $1801 \mathrm{~A}$ & DH18A & $*_{1} 1801$ & & *2201 & & & $*_{0601,}^{* 1702}$ & & & & 1 \\
\hline $1902 \mathrm{~A}$ & & *1902 & & *2206 & & & *1402 & & 1 & & \\
\hline $2002 \mathrm{~A}$ & DH15B & *2002 & *0101 & & & & $*^{*} 0101$ & & & & \\
\hline $2703 \mathrm{~A}$ & & *2703 & $*^{*} 0101$ & *22031 & & & *0103 & & & & 5 \\
\hline $2703 \mathrm{~B}$ & DH23A & *2703 & $*^{*} 0101$ & *22031 & & & *1803 & & & & \\
\hline $2703 \mathrm{C}$ & & $*_{2703}$ & *0203(1) & & & & *0201 & & 1 & & \\
\hline 2703D & & *2703 & ${ }^{*} 0204$ & & & & $* 1808$ & & & & 2 \\
\hline $2703 \mathrm{E}$ & & *2703 & *12012 & *2201 & & & $*_{1001}^{*}, * 0501$ & & & & 3 \\
\hline $3401 \mathrm{~A}$ & & *3401 & *0103 & *22021 & & & *2501 & & 1 & & \\
\hline $3401 B$ & & *3401 & *0203(1) & & & & *0201 & & 1 & & \\
\hline $3401 \mathrm{C}$ & & *3401 & *0301 & & & & *1501 & & 1 & & \\
\hline 4401A & U & $* 4401$ & ${ }^{*} 0103$ & & & & *2701 & & 2 & & \\
\hline
\end{tabular}




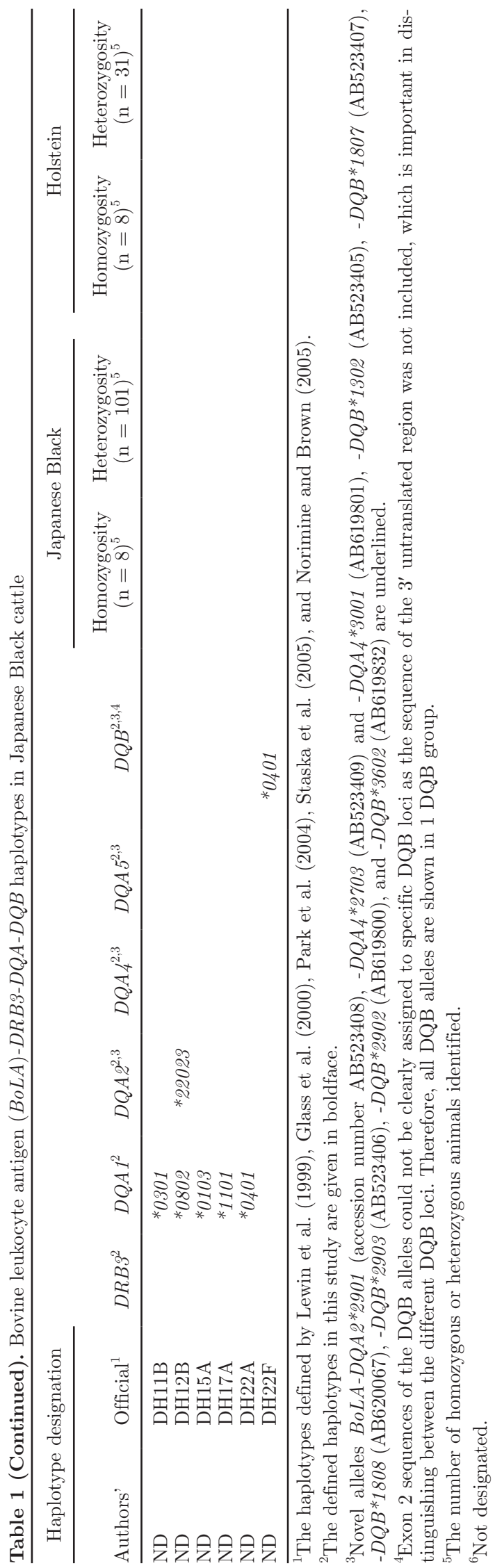

BigDye Terminator Cycle Sequencing Ready Reaction Kits. The sequence data were analyzed using Assign 400ATF version 1.0.2.41 software.

\section{Construction of Minimum Evolution Trees for the BoLA-DQA and BoLA-DQB Genes}

Pairwise genetic distances were calculated on the basis of the BoLA-DQA and - $D Q B$ near-full-length exon 2 amino acid sequences. Amino acid alignment was undertaken using data from the IPD-MHC Database and our own defined sequence data.

The minimum evolution method was used for construction of a phylogenic tree from evolutionary distance data as implemented by the program MEGA 2.1 (Kumar et al., 2004). One thousand bootstrap replicate computations were performed to test the significance of each branch.

\section{RESULTS}

\section{Definition of BoLA-DRB3 Alleles}

To identify BoLA-DRB3-DQA-DQB haplotypes, $B o L A-D R B 3$ genes in 109 Japanese Black and 39 Holstein cattle were identified (Table 1 ). In line with our previous study, 26 different $B o L A-D R B 3$ alleles were detected, each of which had previously been reported in the IPD-MHC database. Twenty-two alleles were from Japanese Black cattle, and 15 alleles from Holstein cattle.

\section{Definition of BoLA-DQA Alleles}

To characterize $B o L A-D Q$ alleles, the same 109 Japanese Black and 39 Holstein cattle were genotyped at 5 BoLA-DQA loci, BoLA-DQA1, -DQA2, -DQA3, $-D Q A 4$, and $-D Q A 5$ (Table 1). From this analysis, we identified 22 previously reported $D Q A$ alleles and 3 novel alleles (AB523408, AB523409, and AB619801). Twenty previously reported alleles and 2 novel alleles (AB523408 and AB523409) were from Japanese Black, and 14 previously reported alleles and 1 novel allele (AB619801) were from Holstein cattle. A minimum evolution tree was constructed based on the amino acid sequences of the $\alpha 1$ domains encoded by the 25 $D Q A$ alleles that were detected in our population of 148 animals, together with 51 previously reported $D Q A$ alleles obtained from the IPD-MHC database or from the GenBank database (Figure 1). The phylogenetic tree clearly shows that these sequences form 2 major branches. The $D Q A 1$ sequences and $D Q A 5$ sequence, which had initially been defined by Gelhaus et al. (1999), are located together on 1 major branch, and 


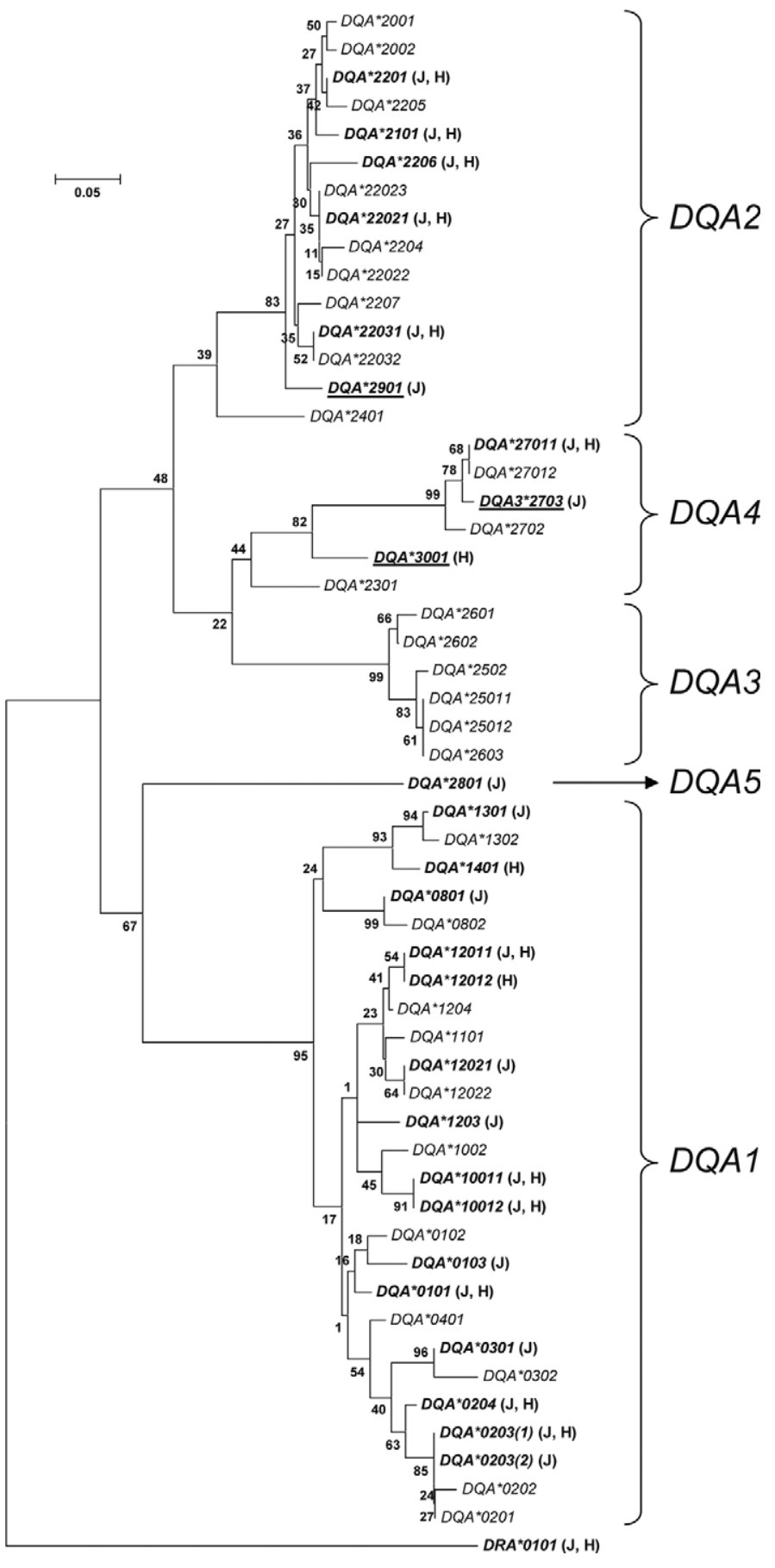

Figure 1. Minimum evolution tree based on the predicted amino acid sequence of the $\alpha 1$ domains encoded by the $25 \mathrm{BoLA}-D Q A$ alleles identified from 148 cattle [109 Japanese Black (J) and 39 Holstein $(\mathrm{H})$ cattle], together with 51 previously reported $D Q A$ alleles from the IPD-MHC database or GenBank database. Numbers indicate the bootstrap percentage that supports each node, and the scale bar indicates the number of substitutions per site in a given interval along the branches. The $D Q A$ alleles defined in this study are indicated by boldface and the 3 novel alleles are underlined. According to previous reports (Ballingall et al., 1998; Gelhaus et al., 1999), these $D Q A$ alleles were assigned to $B o L A-D Q A 1,-D Q A 2,-D Q A 3,-D Q A 4$, and -DQA5 loci. the sequences from $D Q A 2$ and $D Q A 3$ are located on the other major branch. However, $D Q A 3$ was further divided into 2 distinct sequence lineages together with $D Q A$ \& sequences that result from the apparent duplication of the $D Q A 3$ locus, as defined by Ballingall et al. (1998). Thus, $D Q A$ alleles were clustered into 5 loci, consistent with previous reports (Ballingall et al., 1998; Gelhaus et al., 1999). Of the $25 D Q A$ alleles that were sequenced, we assigned 15 to DQA1 ( ${ }^{*} 0101,{ }^{*} 0103$, *0203(1), *0203(2), *0204, *0301, *0801, *10011, *10012, *12011, *12012, *12021, *1203, *1301, and *1401), 6 to DQA2 (*2101, *2201, *22021, *22031, *2206, and AB523408), 3 to DQA4 (*27011, AB523409, and AB619801), and 1 to DQA5 (*2801).

The nucleotide and deduced amino acid sequences of the 3 novel $D Q A$ alleles are shown in Figure 2. Allele designations were officially assigned by the BoLA nomenclature committee of the International Society for Animal Genetics (http://www.projects.roslin.ac.uk/ bola/bolahome.html). The $15 D Q A 2$ alleles shown in Figure 2 were 93.1 to $100 \%$ identical at the nucleotide level and 85.4 to $100 \%$ identical at the amino acid level to the BoLA-DQA2 cDNA clone MQ9 (Morooka et al., 1995). One new allele (AB523408) designated $D Q A 2^{*} 2901$ differed from $D Q A 2^{*} 2201$ at 5 nucleotide positions: $8,19,61,68$, and 87,4 of which were nonsynonymous substitutions at amino acid positions 11 , 25, 27, and 34. Next, the $6 D Q A 4$ alleles shown in Figure 2 were 88.7 to $99.1 \%$ identical at the nucleotide level and 79.5 to $100 \%$ identical at the amino acid level to BoLA-DQA2*27012. The second new allele (AB523409), DQA4*2703, differed from DQA4*27011 at 3 nucleotide positions: 44, 68, and 151, 1 of which was a non-synonymous substitution at amino acid position 55. The third new allele (accession number AB619801), DQA4*3001, differed from DQA4*2301 at 21 nucleotide positions: 15, 17, 20, 24, 25, 87, 90, 101, 106, 131, 164, 179, 180, 182, 189, 192, 193, 210, 213,222 , and 227,11 of which were non-synonymous substitutions at amino acid positions 10, 13, 34, 35, 40, $64,65,68,69,75$, and 79 .

\section{Definition of BoLA-DQB Alleles}

Five BoLA-DQB loci; $D Q B 1, D Q B 2, D Q B 3, D Q B 4$, and $D Q B 5$, were also sequenced using the same 109 Japanese Black and 39 Holstein cattle, and from them were isolated 30 distinct $D Q B$ alleles. The alleles were analyzed by comparison of their sequences and construction of a minimum evolution tree based on the amino acid sequences of the $\beta 1$ domains encoded by the 30 alleles, together with 72 previously reported alleles recorded in the IPD-MHC database. Based on this analysis, the $24 D Q B$ alleles were identified, includ- 
(A)

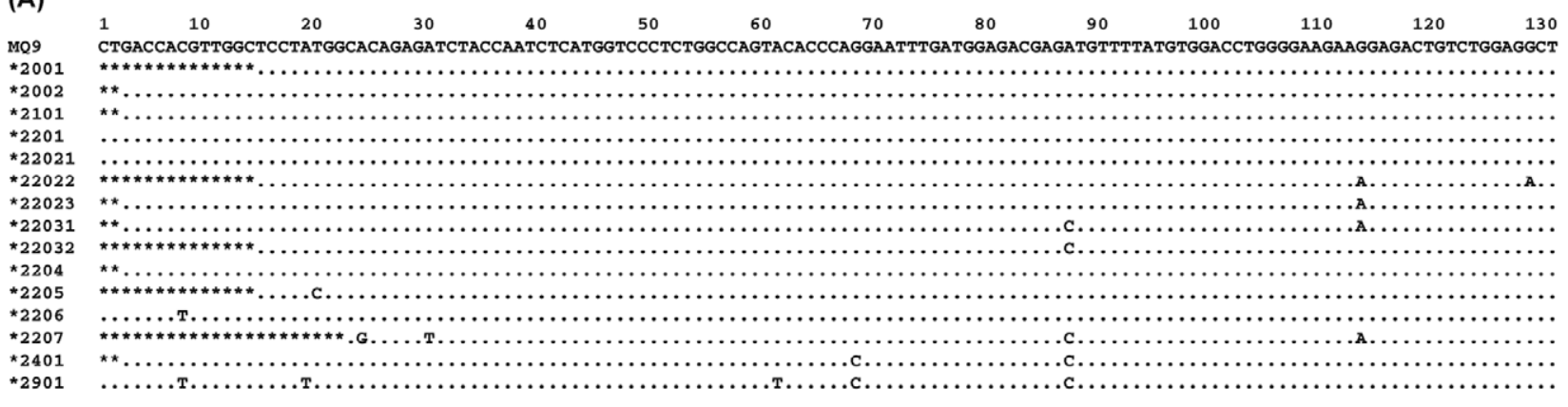

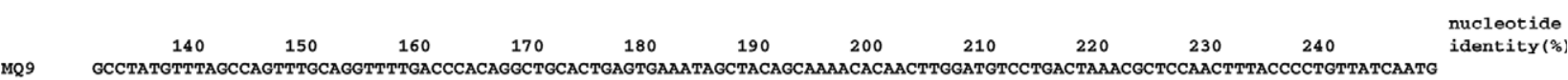

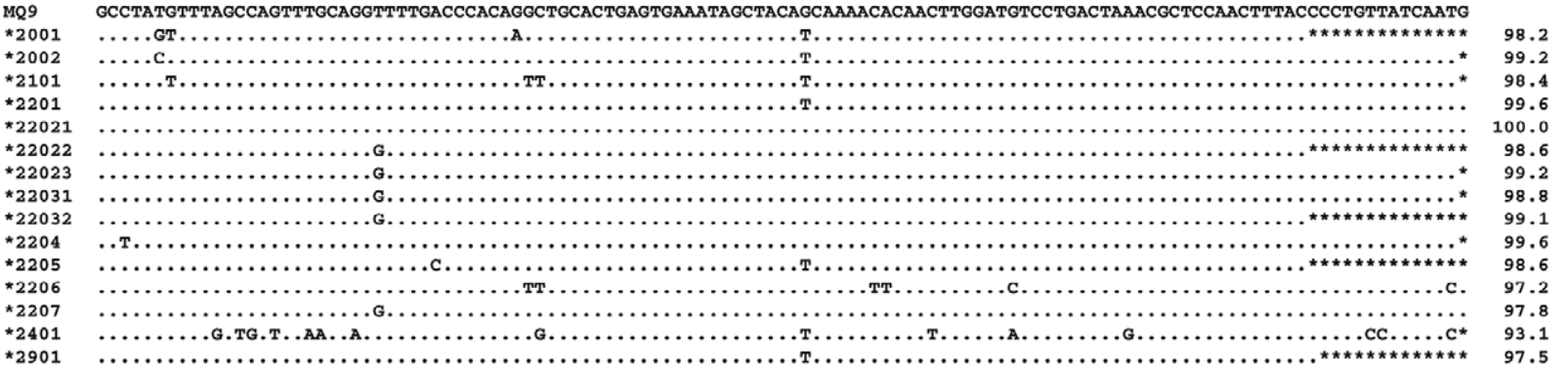

(B)

MQ9
$\star 2001$
$\star 2002$
$\star 2101$
$\star 2201$
$\star 22021$
$\star 22022$
$\star 22023$
$\star 22031$
$\star 22032$
$\star 2204$
$\star 2205$
$\star 2206$
$\star 2207$
$\star 2401$
$\star 2901$

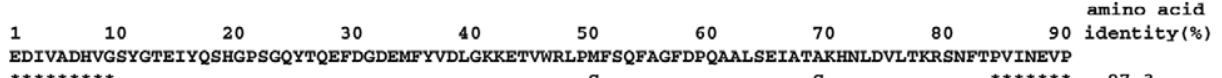

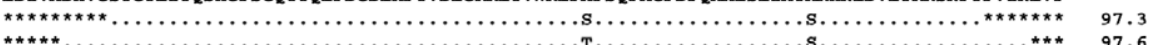

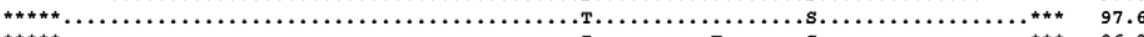

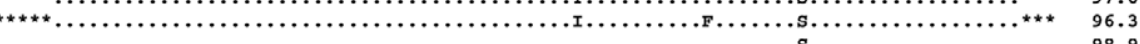
W.W.

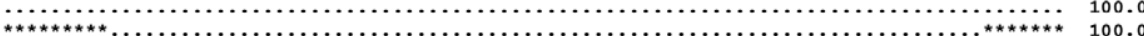

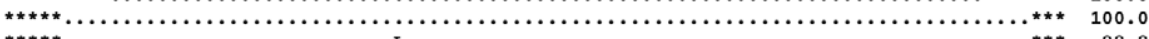

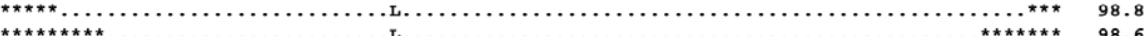

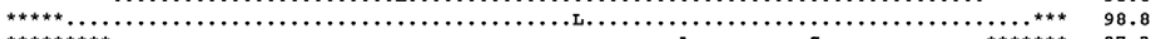

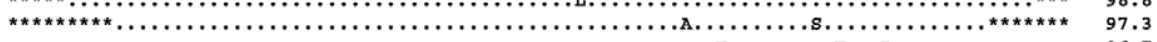

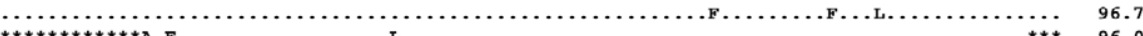

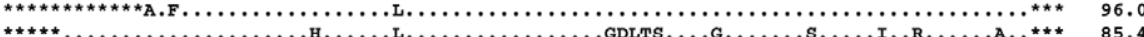

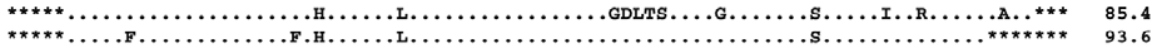

(C)

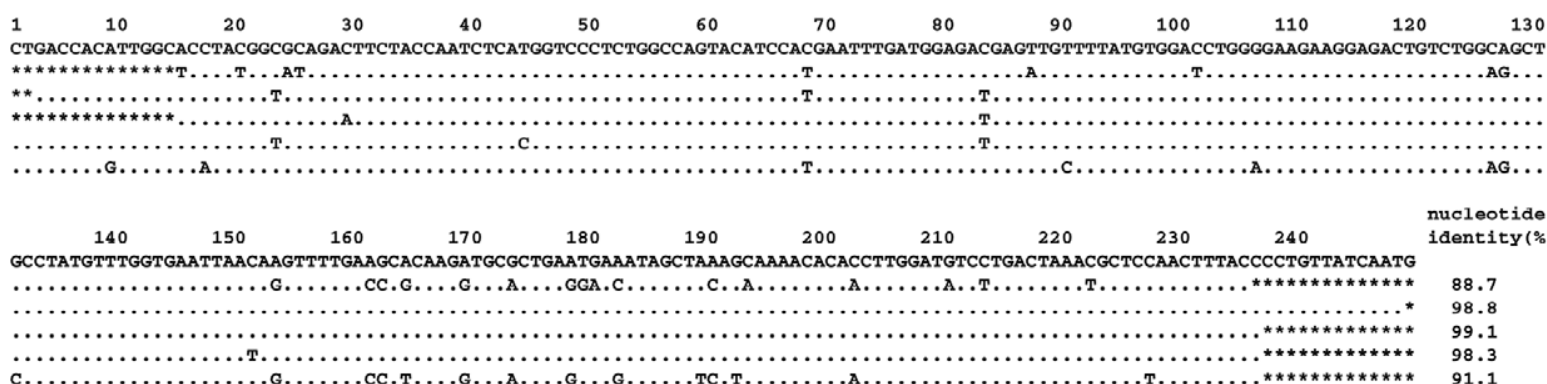

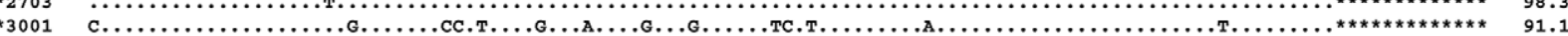

(D)

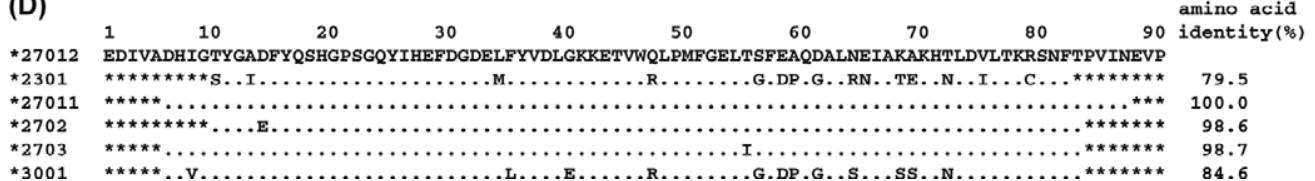

Figure 2. Alignment of the exon 2 nucleotide sequences of the 3 novel alleles BoLA-DQA2*2901 (accession number AB523408) and DQA4*2703 (accession number AB523409) (A) and DQA4*3001 (accession number AB619801) (C), and additional BoLA-DQA2 (accession numbers are Z79515 for *2001, U80866 for *2002, U80867 for *2101, Y07820 for 2201, D50045 for *22021, Z79518 for *22022, U80862 for *22023, U80861 for *22031, Z79514 for *22032, U80865 for *2204, Z79516 for *2205, AB098906 for *2206, AY442304 for *2207, and U80868 for *2401) (A) and additional BoLA-DQA4 alleles (Z79522 for *2301, U80860 for *27011, Y14022 for *27012, and Z79525 for *2702) (C), and the predicted amino acid sequences (B and D). The numbering refers to amino acid positions in the mature protein. Dots indicate sequence identity with respect to the BoLA-DQA2 cDNA clone MQ9 (Morooka et al., 1995) or DQA4*27012. 
ing 6 novel alleles (AB523405, AB523406, AB523407, AB619800, AB619832, and AB620067; Table 1). Eighteen previously reported alleles and 4 novel alleles (AB523405, AB523406, AB523407, and AB619832) were from Japanese Black, and 16 previously reported alleles and 2 novel alleles (AB619800 and AB620067) from Holstein cattle. In contrast to the BoLA-DQA alleles, exon 2 sequences of the $D Q B$ alleles could not be clearly assigned to specific $D Q B$ loci (Figure 3) as the sequence of the 3 ' untranslated region was not included, which is important in distinguishing between the different $D Q B$ loci (Russell, 2000).

The 30 BoLA-DQB alleles that we identified were 82.4 to $100 \%$ identical at the nucleotide level and 71.6 to $100 \%$ identical at the amino acid level to the BoLA-DQB1 cDNA clone NB25 (Dikiniene and Aida, 1995). The aligned nucleotide and deduced amino acid sequences of the 5 novel $D Q B$ alleles are shown in Figure 4. One new allele (accession number ABAB523405), $D Q B^{*} 1302$, differed from $D Q B^{*} 1301$ at 3 nucleotide positions; 76,77 , and 78,1 of which was a non-synonymous substitution at amino acid position 26 . The second new allele (accession number AB523407), DQB*180\%, differed from $D Q B^{*} 1803$ at nucleotide position 199, which was a non-synonymous substitution at amino acid position 67 . The third new allele (accession number AB620067), $D Q B^{*} 1808$, differed from $D Q B^{*} 1803$ at nucleotide position 199, which was a non-synonymous substitution at amino acid position 67. The fourth new allele (accession number AB619800), DQB*2902, differed from $D Q B^{*} 2901$ at 2 nucleotide positions: 25 and 64 , which were non-synonymous substitutions at amino acid positions 9 and 22. The fifth new allele (accession number AB523406), $D Q B^{*} 2903$, differed from $D Q B^{*} 2901$ at 6 nucleotide positions: 148, 169, 170, 209,211 , and 212,4 of which were non-synonymous substitutions at amino acid positions 50, 57, 70, and 71. The sixth new allele (accession number AB619832), $D Q B^{*} 3602$, differed from $D Q B^{*} 3601$ at 2 nucleotide positions: 130 and 131, which were non-synonymous substitutions at amino acid position 44 .

\section{Definition of BoLA DRB3-DQA-DQB Haplotypes in Japanese Black and Holstein Cattle}

The BoLA-DRB3-DQA-DQB haplotypes were sorted in 109 Japanese Black and 39 Holstein cattle according to previously described criteria (Kennedy et al., 2002). The pedigree of our sample population and the hereditary pattern between parent and offspring were also traced. Our newly designated BoLA-DRB3-DQA$D Q B$ haplotypes are shown in Table 1, together with previously published haplotype data. Sixteen animals (8 Japanese Black and 8 Holstein cattle) predicted to

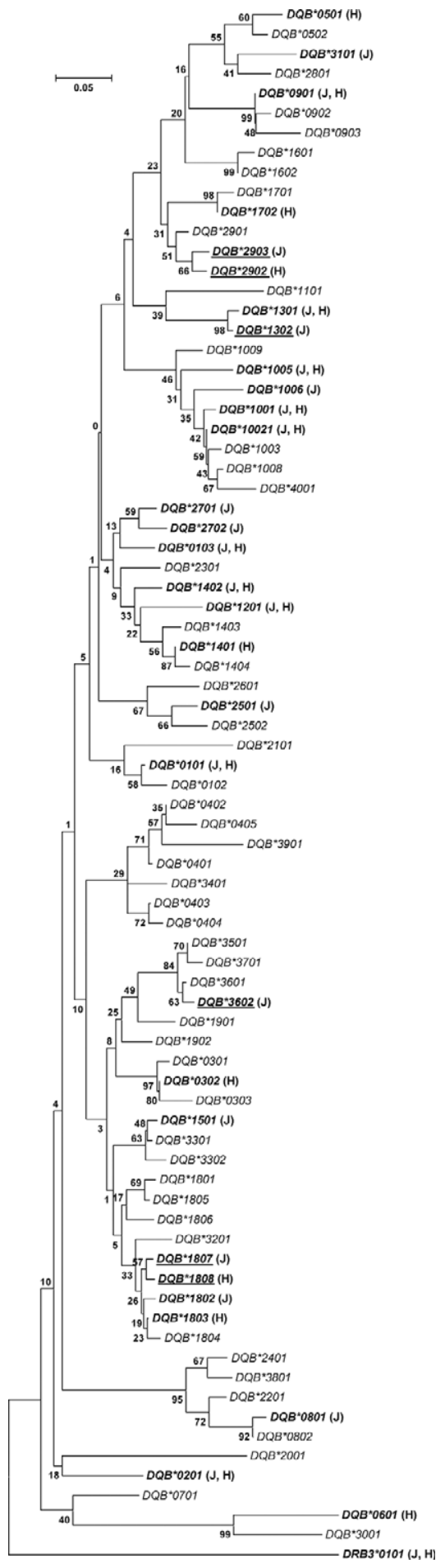

Figure 3. Minimum evolution tree based on the predicted amino acid sequence of the $\beta 1$ domains encoded by 30 BoLA-DQB alleles identified from 148 cattle $[109$ Japanese Black $(\mathrm{J})$ and 39 Holstein $(\mathrm{H})$ cattle], in this study together with 72 previously reported $D Q B$ alleles in the Immuno Polymorphism Database-Major Histocompatibility Complex (IPD-MHC) database. Numbers indicate the bootstrap percentage that supports each node, and the scale bar indicates the number of substitutions per site in a given interval along branches. The $B o L A-D Q B$ alleles defined in this study are indicated by boldface and the 6 novel alleles are underlined. 

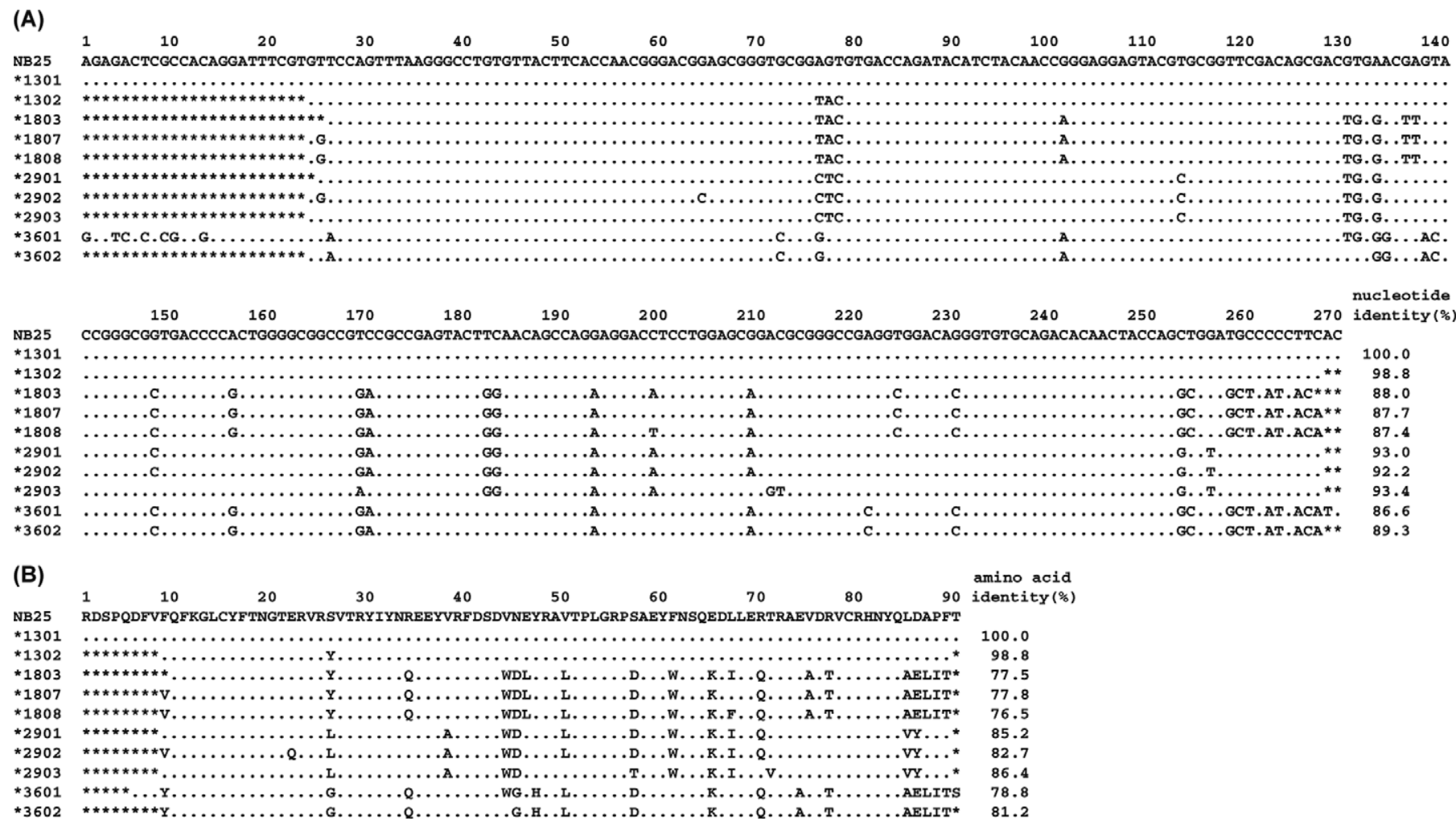

Figure 4. Alignment of the exon 2 nucleotide sequences of the 6 new BoLA-DQB alleles (accession numbers are AB523405 for *1302, AB523407 for *180\%, AB620067 for *1808, AB523406 for *2903, AB619800 for *2902, and AB619832 for *3602) and additional, previously reported BoLA-DQB alleles (accession numbers are D37954 for *1301, AF078159 for *1803, and AJ421635 for *2901) (A) and the predicted amino acid sequences (B). The numbering refers to amino acid positions in the mature protein. Dots indicate sequence identity with respect to the BoLA-DQB cDNA clone NB25 (Dikiniene and Aida, 1995).

be homozygous at all loci were selected, from which 9 different $D R B 3-D Q A-D Q B$ haplotype combinations were identified. In the case of Japanese Black cattle, 1 novel haplotype (1601B) was identified in each of 3 homozygous animals, 1 previously published haplotype (0201A) was identified in each of 2 homozygous animals, and 3 novel haplotypes (0503A, 1302A, and $1601 \mathrm{C}$ ) were identified in a single homozygous animal. In the case of Holstein cattle, 2 previously published haplotypes (0101A and 1501C) were identified in each of 3 homozygous animals, and 1 novel haplotype (1001A) and 1 previously published haplotype (1201B) were identified in a single homozygous animal.

Animals that were heterozygous at a single locus were then examined and 42 distinct haplotypes were predicted: 11 (0101A, 0201A, 0501A, 0701A, 0901A, $1101 \mathrm{~A}, 1101 \mathrm{~B}, 1201 \mathrm{~B}, 14011 \mathrm{~B}, 1501 \mathrm{C}$, and 1801A) of these haplotypes had previously been defined, whereas the remaining 31 haplotypes were considered to be novel. Eighteen (0502A, 0503A, 0504A, 0801D, 0902B, 0902C, 1001B, 1101C, 1201A, 1302A, 14011A, 1601B, $1601 \mathrm{C}, 1701 \mathrm{~A}, 2703 \mathrm{~A}, 2703 \mathrm{D}, 2703 \mathrm{E}$, and $4401 \mathrm{~A})$ of the novel haplotypes and $9(0101 \mathrm{~A}, 0201 \mathrm{~A}, 0501 \mathrm{~A}$,
0701A, 0901A, 1101A, 1201B, 14011B, and 1501C) of the previously reported haplotypes were present in more than 2 heterozygous animals, whereas 12 (0601A, 0801A, 0801C, 1103A, 1301A, 1501A, 1501D, 1902A, $2703 \mathrm{C}, 3401 \mathrm{~A}, 3401 \mathrm{~B}$, and 3401C) of the novel haplotypes and $2(1101 \mathrm{~B}$ and $1801 \mathrm{~A})$ previously reported haplotypes were only found in 1 heterozygous animal. Thus, it appears that $D R B 3-D Q A-D Q B$ haplotypes in cattle are shared by other breeds, and more typing data are needed to establish the full extent of haplotypes in cattle. Although most haplotypes contained 1 or 2 $D Q A$ and $D Q B$ genes, some haplotypes (0504A, 0601A, 0801C, 0801D, 1301A, 1302A, and 1701A) were missing $D Q A$ or $D Q B$, or both, and further research is required to confirm that $D Q$ genes are absent from these haplotypes.

\section{DRB3-DQA1 Haplotype Frequency in Japanese Black and Holstein Cattle}

The BoLA-DRB3-DQA-DQB haplotypes were successfully genotyped in 109 Japanese Black and 39 Holstein cattle by the combination of sequencing of cloned 
Table 2. Frequency of $D R B 3-D Q A 1$ haplotypes in Japanese Black and Holstein cattle

\begin{tabular}{|c|c|c|c|c|c|c|c|}
\hline \multicolumn{2}{|c|}{ Haplotype designation } & \multirow[b]{2}{*}{$D R B 3$} & \multirow[b]{2}{*}{$D Q A 1$} & \multicolumn{2}{|c|}{$\begin{array}{l}\text { Japanese Black } \\
\left(\mathrm{n}=1,014^{2}\right)\end{array}$} & \multicolumn{2}{|c|}{$\begin{array}{l}\text { Holstein } \\
\left(\mathrm{n}=286^{2}\right)\end{array}$} \\
\hline Authors' & Official $^{1}$ & & & $\mathrm{n}$ & $\%$ & $\mathrm{n}$ & $\%$ \\
\hline $0101 \mathrm{~A}$ & DH24A & $* 0101$ & *0101 & 7 & 0.7 & 61 & 21.3 \\
\hline $0201 \mathrm{~A}$ & $\mathrm{DH} 07 \mathrm{~A}$ & *0201 & *0203(1) & 67 & 6.6 & 12 & 4.2 \\
\hline 0501A & DH01A & *0501 & & 0 & 0.0 & 2 & 0.7 \\
\hline 0502A & & *0502 & & 23 & 2.3 & 0 & 0.0 \\
\hline 0503A & & *0503 & ${ }^{*} 0101$ & 134 & 13.2 & 0 & 0.0 \\
\hline $0504 \mathrm{~A}$ & & *0504 & & 12 & 1.2 & 0 & 0.0 \\
\hline 0601A & & ${ }^{*} 0601$ & & 0 & 0.0 & 1 & 0.3 \\
\hline 0701A & DH28A & ${ }^{*} 0701$ & $* 0101$ & 29 & 2.9 & 3 & 1.0 \\
\hline $0801 \mathrm{~A}$ & & *0801 & *0801 & 1 & 0.1 & 0 & 0.0 \\
\hline 0801C & & *0801 & *1203 & 1 & 0.1 & 0 & 0.0 \\
\hline $0801 \mathrm{D}$ & & *0801 & & 3 & 0.3 & 0 & 0.0 \\
\hline 0901E & DH11C & ${ }^{*} 0901$ & *1203 & 3 & 0.3 & 2 & 0.7 \\
\hline $0902 \mathrm{~B}$ or $\mathrm{C}$ & & *0902 & *0204 & 31 & 3.1 & 12 & 4.2 \\
\hline $1001 \mathrm{~A}$ or $\mathrm{B}$ & & *1001 & *10012 & 97 & 9.6 & 26 & 9.1 \\
\hline $1101 \mathrm{~A}$ & DH22H & *1101 & *10011 & 74 & 7.3 & 32 & 11.2 \\
\hline 1101B & DH22E & ${ }^{*} 1101$ & *10012 & 0 & 0.0 & 1 & 0.3 \\
\hline $1101 \mathrm{C}$ & & *1101 & *1301 & 8 & 0.8 & 0 & 0.0 \\
\hline $1103 \mathrm{~A}$ & & *1103 & *0203(2) & 1 & 0.1 & 0 & 0.0 \\
\hline $1201 \mathrm{~A}$ & & *1201 & *10011 & 52 & 5.1 & 1 & 0.3 \\
\hline $1201 \mathrm{~B}$ & DH08A & *1201 & *12011 & 3 & 0.3 & 19 & 6.6 \\
\hline $1301 \mathrm{~A}$ & & *1301 & & 1 & 0.1 & 0 & 0.0 \\
\hline $1302 \mathrm{~A}$ & & *1302 & & 9 & 0.9 & 1 & 0.3 \\
\hline $14011 \mathrm{~A}$ & & $* 14011$ & *10012 & 22 & 2.2 & 0 & 0.0 \\
\hline 14011B & DH27A & *14011 & *1401 & 0 & 0.0 & 16 & 5.6 \\
\hline $1501 \mathrm{~A}$ or $\mathrm{C}$ & DH16A & *1501 & *10011 & 102 & 10.1 & 72 & $25.2^{3}$ \\
\hline 1501D & & *1501 & *10012 & 0 & 0.0 & 2 & 0.7 \\
\hline $1601 \mathrm{~B}$ & & *1601 & *10012 & 253 & $25.0^{3}$ & 0 & 0.0 \\
\hline $1601 \mathrm{C}$ & & ${ }^{*} 1601$ & *12021 & 74 & 7.3 & 1 & 0.3 \\
\hline $1701 \mathrm{D}$ & & *1701 & & 0 & 0.0 & 2 & 0.7 \\
\hline $1801 \mathrm{~A}$ & DH18A & *1801 & & 0 & 0.0 & 2 & 0.7 \\
\hline $1902 \mathrm{~A}$ & & *1902 & & 1 & 0.1 & 0 & 0.0 \\
\hline $2703 \mathrm{~A}$ & & *2703 & *0101 & 0 & 0.0 & 12 & 4.2 \\
\hline $2703 \mathrm{C}$ & & *2703 & *0203(1) & 1 & 0.1 & 0 & 0.0 \\
\hline $2703 \mathrm{D}$ & & *2703 & *0204 & 0 & 0.0 & 2 & 0.7 \\
\hline $2703 \mathrm{E}$ & & *2703 & *12012 & 0 & 0.0 & 4 & 1.4 \\
\hline $3401 \mathrm{~A}$ & & *3401 & ${ }^{*} 0103$ & 1 & 0.1 & 0 & 0.0 \\
\hline $3401 \mathrm{~B}$ & & *3401 & *0203(1) & 1 & 0.1 & 0 & 0.0 \\
\hline $3401 \mathrm{C}$ & & *3401 & *0301 & 1 & 0.1 & 0 & 0.0 \\
\hline $4401 \mathrm{~A}$ & & *4401 & *0103 & 2 & 0.2 & 0 & 0.0 \\
\hline
\end{tabular}

${ }^{1}$ The haplotypes were defined by Lewin et al. (1999), Glass et al. (2000), Park et al. (2004), Staska et al. (2005), and Norimine and Brown (2005). ${ }^{2}$ Haplotype number.

${ }^{3}$ The most frequent haplotypes in each breed are given in bold.

PCR product and PCR-SBT method, as shown in Table 1. To determine which DRB3-DQA1 haplotypes can be defined using only PCR-SBT methods based on allover of defined haplotypes in Table 1, we determined the DRB3-DQA1 haplotypes by PCR-SBT methods alone for BoLA-DRB3 and BoLA-DQA1. We used 507 Japanese Black and 143 Holstein cattle (i.e., 650 cattle, for the purpose of this study; these cattle had been genotyped previously; Miyasaka et al., 2011).

We distinguished 39 out of 42 DRB3-DQA-DQB haplotypes, as detected in this study (Table 2). However, additional genotyping of $D Q A 2 / 3 / 4$ and $D Q B$ is required to accurately determine 3 haplotypes, such as 0902B versus 0902C, 1001A versus 1001B, and 1501A versus 1501C. Thirty-nine DRB3-DQA1 haplotypes were identified, including 29 haplotypes from Japanese Black and 22 haplotypes from Holstein cattle. In Japanese Black cattle, DRB3-DQA1 haplotypes with frequencies greater than $5 \%$ were $0201 \mathrm{~A}\left[D R B 3^{*} 0201\right.$ $\left.D Q A 1^{*} 0203(1)\right], \quad 0503 \mathrm{~A} \quad\left(D R B 3^{*} 0503-D Q A 1^{*} 0101\right)$, $1001 \mathrm{~A}$ or 1001B (DRB3*1001-DQA1*10012), 1101A or $1101 \mathrm{~B} \quad\left(D R B 3^{*} 1101-D Q A 1 * 10011\right), \quad 1201 \mathrm{~A}$ $\left(D R B 3^{*} 1201-D Q A 1^{*} 10011\right), \quad 1501 \mathrm{~A}$ or $1501 \mathrm{C}$ (DRB3*1501-DQA1*10011), 1601B (DRB3*1601$D Q A 1^{* 10012)}$, and 1601C (DRB3*1601-DQA1*12021), whereas haplotypes with frequencies greater than $5 \%$ in Holstein cattle were 0101A $\left(D R B 3^{*} 0101-D Q A 1^{*} 0101\right)$, 1001A or 1001B (DRB3*1001-DQA1*10012), 1101A 
$(D R B 3 * 1101-D Q A 1 * 10011), \quad$ 1201B $\quad(D R B 3 * 1201-$ $\left.D Q A 1^{*} 12011\right)$, 14011B (DRB3*14011-DQA1*1401), and $1501 \mathrm{~A}$ or $1501 \mathrm{C}\left(D R B 3^{*} 1501-D Q A 1^{*} 10011\right)$. The most common $D R B 3-D Q A 1$ haplotype in Japanese Black cattle was 1601B (DRB3*1601-DQA1*10012; $25.0 \%$ of cattle), followed by 0503A $\left(D R B 3^{*} 0503\right.$ $D Q A 1^{*} 0101 ; 13.2 \%$ of cattle). These 2 haplotypes were absent from Holstein cattle. The $1501 \mathrm{~A}$ or $1501 \mathrm{C}$ $\left(D R B 3^{*} 1501-D Q A 1 * 10011\right)$ was the most frequent haplotype in Holstein cattle (25.2\% of cattle) and also occurred moderately frequently in Japanese Black cattle (10.1\%). The 0101A (DRB3*0101-DQA1*0101) was the second most common haplotype in Holsteins $(21.3 \%)$ but was rare among Japanese Black cattle $(0.7 \%)$. Several haplotypes were detected only in a single breed and most of these haplotypes were present at frequencies less than $1 \%$. The 14011A (DRB3*14011$\left.D Q A 1^{*} 10012\right)$ and 14011B (DRB3*14011-DQA1*1401) shared the same DRB3 allele ${ }^{*} 14011$ in both breeds, but each haplotype was only found in a single breed.

\section{DISCUSSION}

In this study, BoLA class II haplotypes were analyzed in Japanese Black and Holstein cattle. Some MHC class II $D Q A-D Q B$ haplotypes are likely to represent mandatory combinations in which a particular $D Q A$ allele must be partnered with a particular $D Q B$ allele. Functional MHC class II molecules can form from either of 2 combinational patterns, inter- or intra-haplotype. Interhaplotype refers to the pairing of gene products encoded by the same chromosome, whereas intrahaplotype refers to the pairing of gene products encoded by a different chromosome. All HLA-DR $\beta$ molecules can pair with $\mathrm{DR} \alpha$, whereas $\mathrm{DQ}$ heterodimer formation is limited (Kwok et al., 1993). The formation of heterodimers has important functional consequences because it influences the structure of the antigen-binding pocket (Siebold et al., 2004). Similar phenomena are observed for BoLA (Norimine and Brown, 2005). All BoLA$D R A / D R B 3$ pairs have the potential to form functional DR molecules, whereas heterodimer formation in DQ molecules is more restricted. For example, although the $D Q A 1^{*} 10011-D Q A 2^{*} 2206-D Q B^{*} 10021-D Q B^{*} 1402$ $(1101 \mathrm{~A})$ haplotype can potentially form 4 intrahaplotypes, it only forms a maximum of 3 interhaplotype pairs $\quad\left(D Q A 1{ }^{*} 10011 / D Q B^{*} 10021, \quad D Q A 2 * 2206 /\right.$ $D Q B^{*} 10021$, and $\left.D Q A 2^{*} 2206 / D Q B^{*} 1402\right)$, indicating that $D Q A 1^{*} 10011$ can only pair with $D Q B^{*} 10021$ (Norimine and Brown, 2005). This hypothesis was supported by the present study, which clearly showed that $D Q A 1^{*} 10011$ was tightly linked to $D Q B^{*} 10021$ (Tables 1 and 2). Thus, our results may indicate strong linkage disequilibrium within $B o L A$ class II genes and that these haplotypes represent very restricted $B o L A$ pairings.

Compared with our previous study of $B o L A-D R B 3$ and $-D Q A 1$ allele frequencies, the present results revealed several similarities between Japanese Black and Holstein cattle in their $D R B 3-D Q A 1$ haplotype frequencies. We previously showed that BoLA-DRB $3^{*} 0503,{ }^{*} 1001$, *1501, and *1601 were common alleles in Japanese Black cattle (Takeshima et al., 2003), and BoLA-DQA1*0101, *10011, and *10012 were also present at high frequency in Japanese Black cattle (Takeshima et al., 2008a). This study showed that 0503A (DRB3*0503-DQA1*0101), $1001 \mathrm{~A}$ or 1001B (DRB3*1001-DQA1*10012), 1501A or 1501C (DRB3*1501-DQA1*10011), and 1601B (DRB3*1601-DQA1*10012) occur at high rates in Japanese Black cattle. Therefore, we predicted that $D R B 3^{*} 0503-D Q A 1^{*} 0101-D Q B^{*} 2702 \quad$ (0503A), $D R B 3 * 1001-D Q A 1 * 10012-D Q A 2 * 2206-D Q B * 10021-$ $D Q B^{*} 1402 \quad$ (1001B), DRB3*1501-DQA1*10011$D Q A 2^{*} 22021-D Q B^{*} 10021-D Q B^{*} 1301$ (1501C), and $D R B{ }^{*} 1601-D Q A 1 * 10012-D Q A 2 * 22021-D Q B * 10021-$ $D Q B^{*} 1302(1601 \mathrm{~B})$ were the predominant Japanese Black haplotypes. In contrast, BoLA-DRB $3^{*} 0101$, ${ }^{*} 1101$ and *1501, and BoLA-DQA1*0101 and *10011 were frequent in Holstein cattle (Takeshima et al., 2003, 2008a). Alleles 0101A (DRB3*0101-DQA1*0101), 1101A (DRB3*1101-DQA1*10011), and 1501A or 1501B (DRB3*1501-DQA1*10011) were also observed at high rates among Holsteins. Therefore, we conclude that $D R B 3^{*} 0101-D Q A 1^{*} 0101-D Q B^{*} 0101$ (0101A), $D R B 3{ }^{*} 1101-D Q A 1 * 10011-D Q A 2 * 2206-D Q B * 10021-$ $D Q B^{*} 1402(1101 \mathrm{~A})$, and $D R B 3^{*} 1501-D Q A 1^{*} 10011$ $D Q A 2^{*} 22021-D Q B^{*} 10021-D Q B^{*} 1301 \quad$ (1501C) are common haplotypes in Holstein cattle.

Duplicated genes such as BoLA-DQA, $-D Q B$, and class $I$ were difficult to genotype due to the difficulty in designing locus-specific primers. The copy number of each gene was dependent on the haplotype, and the nucleotide sequences were frequently very similar between different loci (more so than between different alleles at the same locus). We succeeded in obtaining sequence information for BoLA-DRB3, $-D Q A$, and $-D Q B$ allele combinations for 42 haplotypes. These data will be valuable for allele assignment for Japanese Black cattle and Holstein cattle because different breeds tend to have distinct haplotypes. However, for the assignment of haplotypes from other breeds, it will be necessary to determine the combination of genes in each breed. These problems in genotyping $M H C$ regions may be resolved by the recent development of high-throughput resequencing methods that will facilitate the acquisition of full haplotype sequences. By determining the allele combination in each haplotype, the present results, together with those of other researchers, will be valu- 
able in developing the next generation of genotyping technologies involving the sequencing of entire $M H C$ regions.

It has appeared that most haplotypes have 1 or 2 $D Q A$ and $D Q B$ genes and the numbers of both genes varies between haplotypes (Andersson and Rask, 1988; Sigurdardóttir et al., 1992). However, the present study shows that the 0801A haplotype has 3 DQA alleles, and we were unable to detect $D Q A, D Q B$, or both genes in any of the 0504A, 0601A, 0801C, 0801D, 1301A, 1302A, $1601 \mathrm{~A}$, or $1701 \mathrm{~A}$ haplotypes. In this study, typing data of the 0801A haplotype were confirmed by several clonings after PCR amplifications and PCR-SBT methods, indicating that the bovine genome may contain $3 D Q A$ genes. By contrast, it is uncertain whether the lack of amplification in haplotypes that fail to detect $D Q A$ or $D Q B$ genes was really due to a null allele or a sequence polymorphism in the primer site. Indeed, Sigurdardóttir et al. (1992) also failed to assign some $D Q B$ alleles using the same primers. To solve this problem, additional more effective locus-specific primers and more typing data are needed to exactly define the diversity of BoLA class II haplotypes.

In conclusion, the results of the present study may provide useful information for disease association studies, the development of effective vaccines, and the development of breeding strategies for better livestock in the future. The BoLA class II $D R$ and $D Q$ genes appear to be in strong linkage disequilibrium. Most of the class II haplotypes have been determined for the Holstein breed, and the haplotypes of the other breed were still unknown. The DRB3 and $D Q A$ allele distributions have been reported to be similar for the Holstein and Japanese Black breeds (Takeshima et al., 2003, 2008a). However, in this study, we have clearly shown that this allele distribution is quite distinct between these 2 breeds with respect to class II haplotype distribution. This suggests that it is important to identify haplotypes when performing disease association studies to detect the disease-susceptible class II gene, and we strongly recommend that the $D Q-D R$ haplotype be studied in various distinct cattle breeds.

\section{ACKNOWLEDGMENTS}

We thank Kazuhiko Kobayashi and Tamako Matsuhashi of Gifu Prefectural Livestock Research Institute (Takayama, Gifu, Japan), and Kazuki Ishibashi of Chuo Livestock Hygiene Service Center (Kurume, Fukuoka, Japan) for helpful sampling; and Yuki Matsumoto, Kado Mayu, Akimi Miki, and other members of the Viral Infectious Diseases Unit, RIKEN (Wako, Saitama, Japan), for excellent technical assistance, kind help, and suggestions. We are grateful to the Support
Unit for Bio-Material Analysis, RIKEN BSI Research Resources Center, for help with sequence analysis. This work was supported by Grants-in-Aid for Scientific Research [A (18255013) and B (22405040)] from the Japan Society for the Promotion of Science (JSPS) and by a Grant from the Program for the Promotion of Basic and Applied Research for Innovations in BioOriented Industry.

\section{REFERENCES}

Aida, Y. 1995. Characterization and expression of bovine MHC class II genes. Bulletin dela Société Franco-Japonaise des Sciences Vétérinaires 6:17-24.

Andersson, L., and L. Rask. 1988. Characterization of the MHC class II region in cattle. The number of $D Q$ genes varies between haplotypes. Immunogenetics 27:110-120.

Ballingall, K. T., A. Luyai, and D. J. McKeever. 1997. Analysis of genetic diversity at the $D Q A$ loci in African cattle: Evidence for a BoLA-DQA3 locus. Immunogenetics 46:237-244.

Ballingall, K. T., B. S. Marasa, A. Luyai, and D. J. McKeever. 1998 Identification of diverse $B o L A D Q A 3$ genes consistent with nonallelic sequences. Anim. Genet. 29:123-129.

Dikiniene, N., and Y. Aida. 1995. Cattle cDNA clones encoding MHC class II $D Q B 1$ and $D Q B 2$ genes. Immunogenetics 42:75.

Elsik, C. G., R. L. Tellam, K. C. Worley, R. A. Gibbs, D. M. Muzny, G. M. Weinstock, D. L. Adelson, E. E. Eichler, L. Elnitski, R. Guigó, D. L. Hamernik, S. M. Kappes, H. A. Lewin, D. J. Lynn, F. W. Nicholas, A. Reymond, M. Rijnkels, L. C. Skow, E. M. Zdobnov, L. Schook, J. Womack, T. Alioto, S. E. Antonarakis, A. Astashyn, C. E. Chapple, H. C. Chen, J. Chrast, F. Câmara, O. Ermolaeva, C. N. Henrichsen, W. Hlavina, Y. Kapustin, B. Kiryutin, P. Kitts, F. Kokocinski, M. Landrum, D. Maglott, K. Pruitt V. Sapojnikov, S. M. Searle, V. Solovyev, A. Souvorov, C. Ucla, C. Wyss, J. M. Anzola, D. Gerlach, E. Elhaik, D. Graur, J. T. Reese, R. C. Edgar, J. C. McEwan, G. M. Payne, J. M. Raison, T. Junier, E. V. Kriventseva, E. Eyras, M. Plass, R. Donthu, D. M. Larkin, J. Reecy, M. Q. Yang, L. Chen, Z. Cheng, C. G. Chitko-McKown, G. E. Liu, L. K. Matukumalli, J. Song, B. Zhu, D. G. Bradley, F. S. Brinkman, L. P. Lau, M. D. Whiteside, A. Walker, T. T. Wheeler, T. Casey, J. B. German, D. G. Lemay, N. J. Maqbool, A. J. Molenaar, S. Seo, P. Stothard, C. L. Baldwin, R. Baxter, C. L. Brinkmeyer-Langford, W. C. Brown, C. P. Childers, T. Connelley, S. A. Ellis, K. Fritz, E. J. Glass, C. T. Herzig, A. Iivanainen, K. K. Lahmers, A. K. Bennett, C. M. Dickens, J. G. Gilbert, D. E. Hagen, H. Salih, J. Aerts, A. R. Caetano, B. Dalrymple, J. F. Garcia, C. A. Gill, S. G. Hiendleder, E. Memili, D. Spurlock, J. L. Williams, L. Alexander, M. J. Brownstein, L. Guan, R. A. Holt, S. J. Jones, M. A. Marra, R. Moore, S. S. Moore, A. Roberts, M. Taniguchi, R. C. Waterman, J. Chacko, M. M. Chandrabose, A. Cree, M. D. Dao, H. H. Dinh, R. A. Gabisi, S. Hines, J. Hume, S. N. Jhangiani, V. Joshi, C. L. Kovar, L. R. Lewis, Y. S. Liu, J. Lopez, M. B. Morgan, N. B. Nguyen, G. O. Okwuonu, S. J. Ruiz, J. Santibanez, R. A. Wright, C. Buhay, Y. Ding, S. Dugan-Rocha, J. Herdandez, M. Holder, A. Sabo, A. Egan, J. Goodell, K. WilczekBoney, G. R. Fowler, M. E. Hitchens, R. J. Lozado, C. Moen, D. Steffen, J. T. Warren, J. Zhang, R. Chiu, J. E. Schein, K. J. Durbin, P. Havlak, H. Jiang, Y. Liu, X. Qin, Y. Ren, Y. Shen, H. Song, S. N. Bell, C. Davis, A. J. Johnson, S. Lee, L. V. Nazareth, B. M. Patel, L. L. Pu, S. Vattathil, R. L. Williams Jr., S. Curry, C. Hamilton, E. Sodergren, D. A. Wheeler, W. Barris, G. L. Bennett, A. Eggen, R. D. Green, G. P. Harhay, M. Hobbs, O. Jann, J. W. Keele, M. P. Kent, S. Lien, S. D. McKay, S. McWilliam, A. Ratnakumar, R. D. Schnabel, T. Smith, W. M. Snelling, T. S. Sonstegard, R. T. Stone, Y. Sugimoto, A. Takasuga, J. F. Taylor, C. P. Van Tassell, M. D. Macneil, A. R. Abatepaulo, C. A. Abbey, V. Ahola, I. G. Almeida, A. F. Amadio, E. Anatriello, S. M. Bahadue, F. H. Biase, C. R. Boldt, J. A. Carroll, W. A. Carvalho, E. P. Cer- 
velatti, E. Chacko, J. E. Chapin, Y. Cheng, J. Choi, A. J. Colley, T. A. de Campos, M. De Donato, I. K. Santos, C. J. de Oliveira, H. Deobald, E. Devinoy, K. E. Donohue, P. Dovc, A. Eberlein, C. J. Fitzsimmons, A. M. Franzin, G. R. Garcia, S. Genini, C. J. Gladney, J. R. Grant, M. L. Greaser, J. A. Green, D. L. Hadsell, H. A. Hakimov, R. Halgren, J. L. Harrow, E. A. Hart, N. Hastings, M. Hernandez, Z. L. Hu, A. Ingham, T. Iso-Touru, C. Jamis, K. Jensen, D. Kapetis, T. Kerr, S. S. Khalil, H. Khatib, D. Kolbehdari, C. G. Kumar, D. Kumar, R. Leach, J. C. Lee, C. Li, K. M. Logan, R. Malinverni, E. Marques, W. F. Martin, N. F. Martins, S. R. Maruyama, R. Mazza, K. L. McLean, J. F. Medrano, B. T. Moreno, D. D. More, C. T. Muntean, H. P. Nandakumar, M. F. Nogueira, I. Olsaker, S. D. Pant, F. Panzitta, R. C. Pastor, M. A. Poli, N. Poslusny, S. Rachagani, S. Ranganathan, A. Razpet, P. K. Riggs, G. Rincon, N. Rodriguez-Osorio, S. L. Rodriguez-Zas, N. E. Romero, A. Rosenwald, L. Sando, S. M. Schmutz, L. Shen, L. Sherman, B. R. Southey, Y. S. Lutzow, J. V. Sweedler, I. Tammen, B. P. Telugu, J. M. Urbanski, Y. T. Utsunomiya, C. P. Verschoor, A. J. Waardenberg, Z. Wang, R. Ward, R. Weikard, T. H. Welsh Jr., S. N. White, L. G. Wilming, K. R. Wunderlich, J. Yang, and F. Q. Zhao. 2009. The genome sequence of taurine cattle: A window to ruminant biology and evolution. Science 324:522-528.

Gelhaus, A., B. Förster, C. Wippern, and R. D. Horstmann. 1999. Evidence for an additional cattle $D Q A$ locus, BoLA-DQA5. Immunogenetics 49:321-327.

Glass, E. J., R. A. Oliver, and G. C. Russell. 2000. Duplicated DQ haplotypes increase the complexity of restriction element usage in cattle. J. Immunol. 165:134-138.

Kennedy, L. J., A. Barnes, G. M. Happ, R. J. Quinnell, O. Courtenay, S. D. Carter, W. E. Ollier, and W. Thomson. 2002. Evidence for extensive DLA polymorphism in different dog populations. Tissue Antigens 60:43-52.

Kumar, S., K. Tamura, and M. Nei. 2004. MEGA3: Integrated software for Molecular Evolutionary Genetics Analysis and sequence alignment. Brief. Bioinform. 5:150-163.

Kwok, W. W., S. Kovats, P. Thurtle, and G. T. Nepom. 1993. HLADQ allelic polymorphisms constrain patterns of class II heterodimer formation. J. Immunol. 150:2263-2272.

Lewin, H. A., G. C. Russell, and E. J. Glass. 1999. Comparative organization and function of the major histocompatibility complex of domesticated cattle. Immunol. Rev. 167:145-158.

Mikko, S., and L. Andersson. 1995. Extensive MHC class II DRB3 diversity in African and European cattle. Immunogenetics 42:408413.

Miyasaka, T., S.-N. Takeshima, Y. Matsumoto, N. Kobayashi, T. Matsuhashi, Y. Miyazaki, Y. Tanabe, K. Ishibashi, H. Sentsui, and Y. Aida. 2011. The diversity of bovine MHC class II DRB3 and $D Q A 1$ alleles in different herds of Japanese Black and Holstein cattle in Japan. Gene 472:42-49.

Morooka, A., M. Asahina, C. Kohda, S. Tajima, M. Niimi, Y. Nishino, M. Sugiyama, and Y. Aida. 1995. Nucleotide sequence and the molecular evolution of a new A2 gene in the DQ subregion of the bovine major histocompatibility complex. Biochem. Biophys. Res. Commun. 212:110-117.

Norimine, J., and W. C. Brown. 2005. Intrahaplotype and interhaplotype pairing of bovine leukocyte antigen DQA and DQB molecules generate functional DQ molecules important for priming $\mathrm{CD} 4^{+}$ T-lymphocyte responses. Immunogenetics 57:750-762.

Park, Y. H., Y. S. Joo, J. Y. Park, J. S. Moon, S. H. Kim, N. H. Kwon, J. S. Ahn, W. C. Davis, and C. J. Davies. 2004. Characterization of lymphocyte subpopulations and major histocompatibility com- plex haplotypes of mastitis-resistant and susceptible cows. J. Vet. Sci. 5:29-39.

Russell, G. C. 2000. Sequence duplication at the $3^{\prime}$ end of BoLA$D Q B$ genes suggests multiple allelic lineages. Immunogenetics 52:101-106.

Schwab, A. E., T. G. Geary, P. Baillargeon, A. J. Schwab, and G. Fecteau. 2009. Association of BoLA DRB3 and DQA1 alleles with susceptibility to Neospora caninum and reproductive outcome in Quebec Holstein cattle. Vet. Parasitol. 165:136-140.

Siebold, C., B. E. Hansen, J. R. Wyer, K. Harlos, R. E. Esnouf, A. Svejgaard, J. I. Bell, J. L. Strominger, E. Y. Jones, and L. Fugger. 2004. Crystal structure of HLA-DQ0602 that protects against type 1 diabetes and confers strong susceptibility to narcolepsy. Proc. Natl. Acad. Sci. USA 101:1999-2004.

Sigurdardóttir, S., C. Borsch, K. Gustafsson, and L. Andersson. 1992 Gene duplications and sequence polymorphism of bovine class II DQB genes. Immunogenetics 35:205-213.

Staska, L. M., C. J. Davies, W. C. Brown, T. C. McGuire, C. E. Suarez, J. Y. Park, B. A. Mathison, J. R. Abbott, and T. V. Baszler. 2005. Identification of vaccine candidate peptides in the NcSRS2 surface protein of Neospora caninum by using $\mathrm{CD} 4^{+}$cytotoxic T lymphocytes and gamma interferon-secreting $\mathrm{T}$ lymphocytes of infected Holstein cattle. Infect. Immun. 73:1321-1329.

Takeshima, S., S. Chen, M. Miki, M. Kado, and Y. Aida. 2008a. Distribution and origin of bovine major histocompatibility complex class II DQA1 genes in Japan. Tissue Antigens 72:195-205.

Takeshima, S. Y. Matsumoto, J. Chen, T. Yoshida, H. Mukoyama, and Y. Aida. 2008b. Evidence for cattle major histocompatibility complex (BoLA) class II DQA1 gene heterozygote advantage against clinical mastitis caused by Streptococci and Escherichia species. Tissue Antigens 72:525-531.

Takeshima, S., Y. Nakai, M. Ohta, and Y. Aida. 2002. Short communication: Characterization of $D R B 3$ alleles in the MHC of Japanese shorthorn cattle by polymerase chain reaction-sequence-based typing. J. Dairy Sci. 85:1630-1632.

Takeshima, S., N. Saitou, M. Morita, H. Inoko, and Y. Aida. 2003. The diversity of bovine MHC class II DRB3 genes in Japanese Black, Japanese Shorthorn, Jersey and Holstein cattle in Japan. Gene 316:111-118

Takeshima, S.-N., and Y. Aida. 2006. Structure, function and disease susceptibility of the bovine major histocompatibility complex. Anim. Sci. J. 77:138-150.

Takeshima, S.-N., A. Sarai, N. Saitou, and Y. Aida. 2009. MHC class II DR classification based on antigen-binding groove natural selection. Biochem. Biophys. Res. Commun. 385:137-142.

Untalan, P. M., J. H. Pruett, and C. D. Steelman. 2007. Association of the bovine leukocyte antigen major histocompatibility complex class II DRB3*4401 allele with host resistance to the Lone Star tick, Amblyomma americanum. Vet. Parasitol. 145:190-195.

Wang, K., D. Sun, R. Xu, and Y. Zhang. 2005. Identification of 19 new BoLA-DQB alleles. Anim. Genet. 36:166-167.

Wang, K., D. X. Sun, and Y. Zhang. 2007. Identification of genetic variations of exon 2 of $B o L A-D Q B$ gene in five Chinese yellow cattle breeds. Int. J. Immunogenet. 34:115-118.

Xu, A., M. J. van Eijk, C. Park, and H. A. Lewin. 1993. Polymorphism in BoLA-DRB3 exon 2 correlates with resistance to persistent lymphocytosis caused by bovine leukemia virus. J. Immunol. 151:6977-6985. 